\title{
AGGRESSIVE ANGIOMYXOMA OF VULVA
}

\author{
Madhav Panthi $i^{1^{*}}$, Neeta Kafle ${ }^{2}$, Tarun Pradhan ${ }^{3}$
}

\section{Affiliation}

1. Intern, Department of Obstetrics and Gynecology, Birat Medical College and Teaching Hospital, Nepal

2. Assistant Professor, Department of Pathology, Birat Medical College and Teaching Hospital, Nepal

3. Associate Professor, Department of Obstetrics and Gynecology, Birat Medical College and Teaching Hospital, Nepal

\section{ARTICLE INFO}

Received : 09 July, 2021

Accepted : 28 December, 2021

Published : 21 February, 2022

(c) Authors retain copyright and grant the journal right of first publication with the work simultaneously licensed under Creative Commons Attribution License CC - BY 4.0 that allows others to share the work with an acknowledgment of the work's authorship and initial publication in this journal.

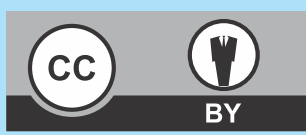

CR 44

DOI: https://doi.org/10.3126/bjhs.v6i3.43246

\section{* Corresponding Author \\ Dr. Madhav Panthi Intern}

Obstetrics and Gynecology

Birat Medical College and Teaching Hospital, Nepal Department of Obstetrics and Gynecology

Email: madhavpanthi32@gmail.com

ORCID ID: https://orcid.org/0000-0002-4471-9178

\section{Citation}

Aggressive Angiomyxoma of Vulva. Madhav Panthi, Neeta Kafle, Tarun Pradhan. BJHS 2021;6(3)16.1661-1664.

\section{ABSTRACT}

Aggressive angiomyxoma is a rare, slowly growing, and benign tumor of mesenchymal origin that usually occurs in the pelvis and perineum of young females. Steeper and Rosai in 1983, first described angiomyxoma. The term "aggressive" underlines the tumour's locally infiltrative nature and high risk for local recurrence. The rate of relapse varies from $35 \%$ to $72 \%$, however, it rarely metastasizes so it has an overall good prognosis. Diagnosis is mainly made on histopathology after surgical resection. The optimal treatment for aggressive angiomyxoma is wide local excision with tumor free margin. We here report a case of aggressive angiomyxoma in 22 years female who presented with mass on left labia majora.

\section{KEYWORDS}

Aggressive angiomyxoma, local recurrence, mesenchymal tumor 


\section{INTRODUCTION}

Angiomyxoma is soft tissue neoplasm with a predilection for pelvic and perineal regions and has a tendency for local recurrence. It is composed of small stellate and spindle cells in a myxoedematousstroma with entrapped regional structures. ${ }^{1}$ Aggressive angiomyxoma is rare. Steeper and Rosai in 1983, first described angiomyxoma and reported a case series of 9 female patients. ${ }^{2}$ There is predilection for the perineum of reproductive-age women. Very few cases have also been described in men, usually involving the scrotum. Female to male ratio is 6.6/1 and the term "aggressive" underlines the tumour's locally infiltrative nature, but mostly the high rate of local recurrence. ${ }^{3}$ It usually presents as a vulval polyp and is diagnosed on histopathology. Estrogen and progesterone receptors are commonly found in aggressive angiomyxoma. ${ }^{4}$ There is lack of agreement among pathologists regarding the tumour pathogenesis; however, a fibroblastic/myofibroblastic origin seems most likely. ${ }^{5}$ We here report first diagnosed case of aggressive angiomyxoma in our institution in 22 year old female.

\section{CASE PRESENTATION}

A 22 years old female presented to our gynecology outpatient department with mass on the left labia majora for one year. Initially the mass was small and increased in size for last six months. There was no history of any vulvar or vaginal discharge, bleeding or pain except a hanging sensation while standing. Menstrual cycles were irregular ranging from 35-70 days but with a normal flow. There was no history of prior perineal surgery. There was no significant past history, no significant family history. Examination of perineum revealed a pedunculated mass from left labia majora measuring approximately $10 \mathrm{~cm} \times 8 \mathrm{~cm} \times 4 \mathrm{~cm}$ with stalk $4 \mathrm{~cm}$ (Figure1). There was no sensation of pain and touch over the mass. Overlying skin showed some area of excoriation and ulcer. There was no associated regional or distant lymphadenopathy. Other systemic examinations were found to be normal. Preoperative investigations were within normal limits. Ultrasonography of abdomen and pelvic had nothing to add. Patient was planned for wide local excision of the mass. Mass was excised under spinal anesthesia and was sent to histopathological examination. Mass was pedunculated and measured $9 \mathrm{~cm} \times 6 \mathrm{~cm} \times 3 \mathrm{~cm}$ with $5 \mathrm{~cm}$ stalk. Perineal area was healthy after excision (Figure 2). There was no reactionary hemorrhage on postoperative period. On gross examination the mass was soft in consistency with glistening, gelatinous cut surface (Figure 3). Histopathogical examination revealed proliferation of many variable sized thick and thin walled blood vessels. There was proliferation of spindle shaped cells and stellate shaped cells, stroma was edematous and showed focal myxoid areas intermingled with collagen fibers (Figure 4,5). On the background of clinical presentation and histopathologicalreport diagnosis of aggressive angiomyxoma was made out. The patient had complete resolution of the swelling and remains asymptomatic during our first six months of follow up.

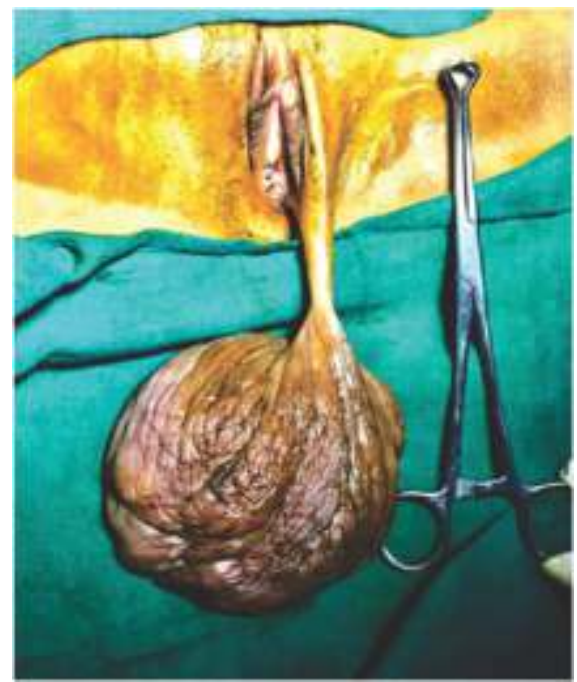

Figure 1: Gross pedunculatedmass with stalk.

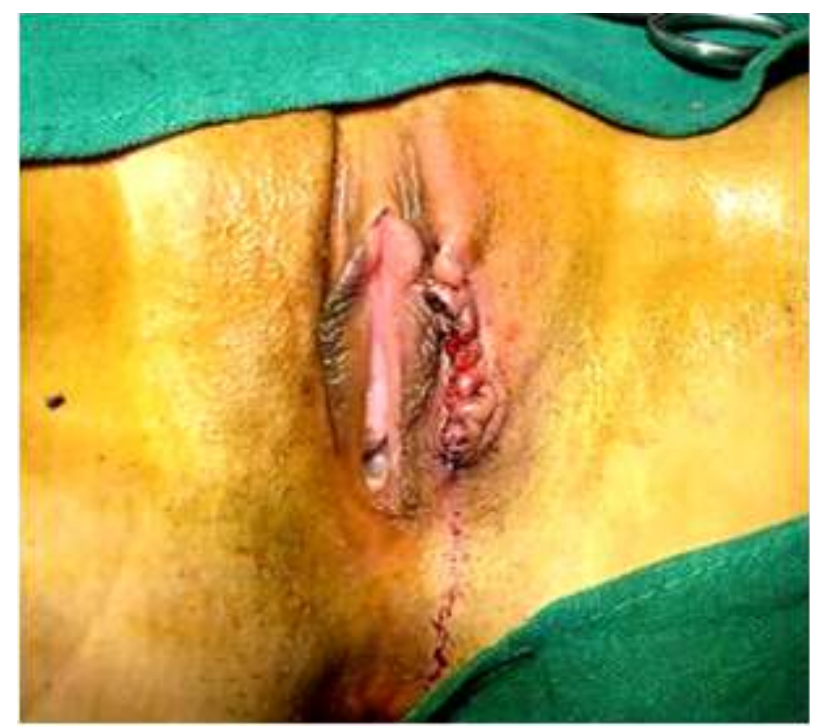

Figure 2: After excision of the mass

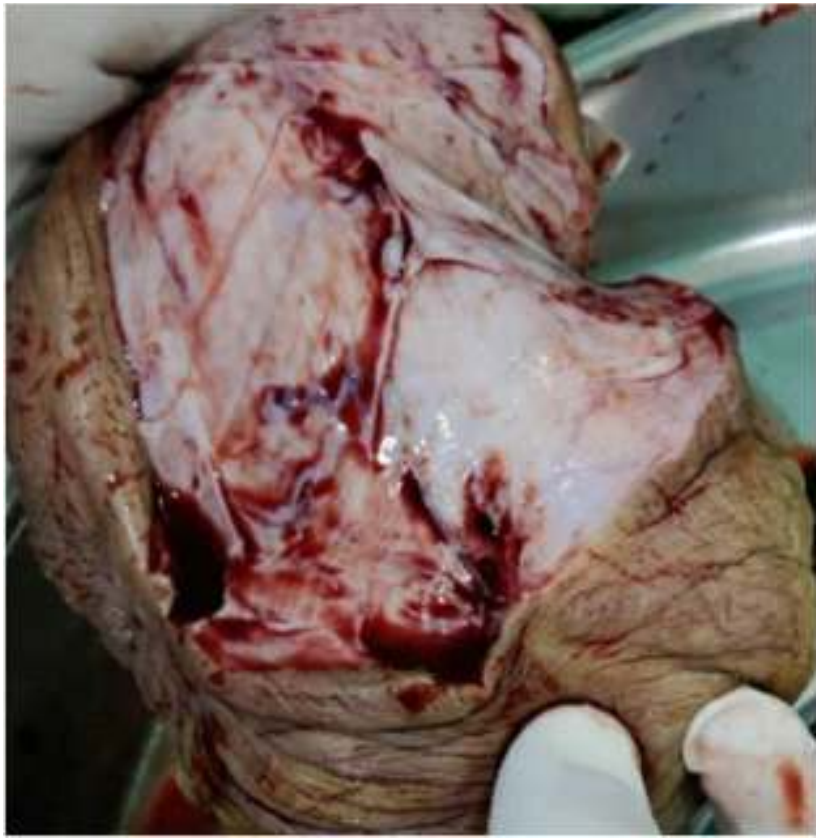

Figure 3: Shows glistening, gelatinous cut surface. 

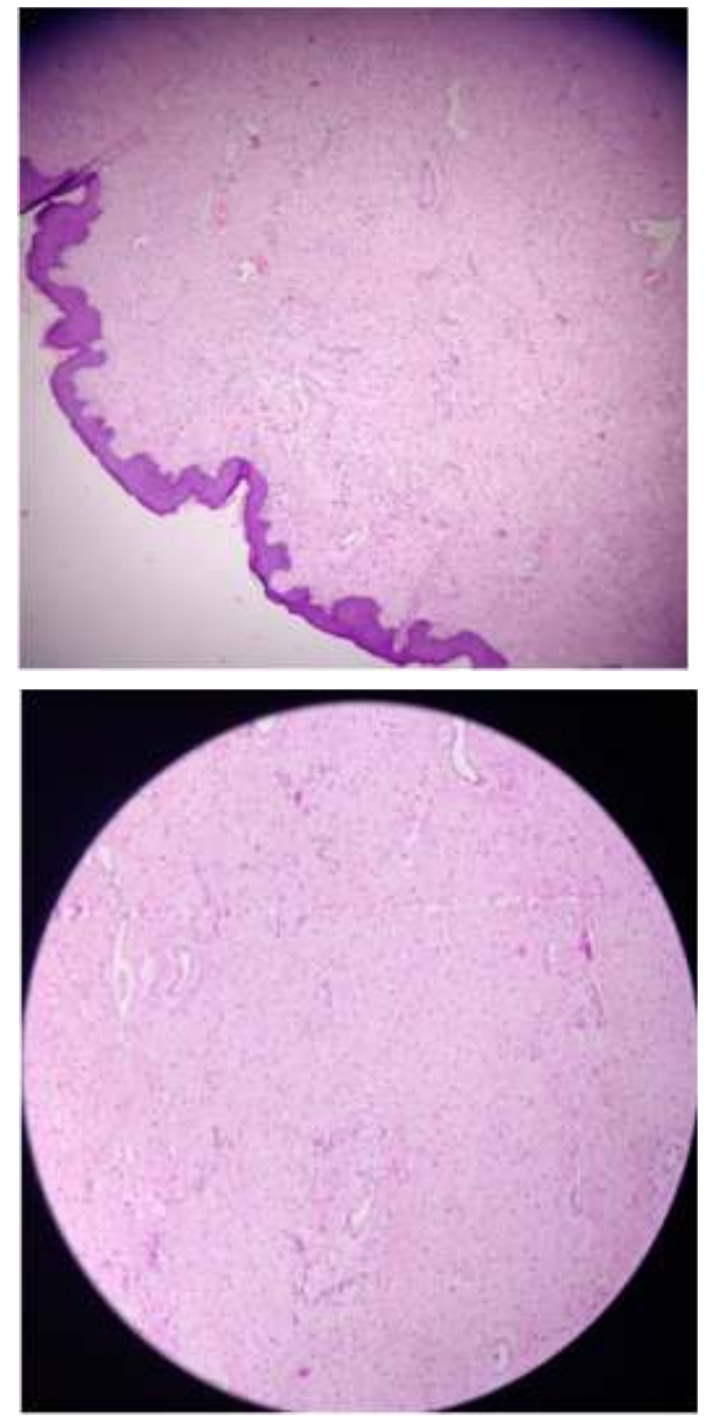

Figure 4 and 5: Histopathological pictures of Aggressive Angiomyxoma under low and high power respectively.

\section{DISCUSSION}

In general, angiomyxomas are classified either as superficial (also known as cutaneous myxoma) or aggressive angiomyxoma. Superficial angiomyxoma may occur in the setting of Carney complex. ${ }^{56}$ This lesions is observed predominantly in male middle aged adults and can arise anywhere in the superficial tissues, but mostly it involves the trunk, lower extremities, and head and neck. Clinically, most lesions appear as slowly growing polypoid cutaneous lesions and are easily confused with a cyst, skin tag, or neurofibroma. ${ }^{5}$ But aggressive angiomyxomasmainly occurs on the vagina, vulva pelvic cavity, perineum, hips and crissum in reproductive female. The rate of relapse varies from $35 \%$ to $72 \%{ }^{7}$ However, it rarely metastasizes so it has an overall good prognosis. Tumor size is highly variable and ranges from $1 \mathrm{~cm}$ to $60 \mathrm{~cm}$. Most patients with deep aggressive angiomyxoma present with a slow-growing mass in the pelvicoperineal region that is either asymptomatic or associated with regional pain, dyspareunia, or a pressure-like sensation. But in our case the mass was rapidly growing over six months and was asymptomatic otherwise except the sensation of hanging mass. The lesions frequently have a lobular contour with adherence to fat, muscle, and other regional structures. A soft, firm, or rubbery consistency may be present, and a glistening, myxooedematous, pink or reddish-tan cut surface is usually evident. Cystic change has occasionally been noted. ${ }^{1}$ Differential diagnosis of aggressive angiomyxoma includes angiomyofibroblastoma, bartholin gland cyst, vaginal polyp, leiomyoma , leiomyosarcoma, lymphangioma, malignant fibrohistiocytoma, myxolipoma, myxoid leiomyoma, myxoidneurofibroma, slerosing hemagioma. ${ }^{10}$ Sometimes it may misdiagnosed with an obturator hernia. ${ }^{11}$ The optimal treatment for aggressive angiomyxomais wide local excision with tumor free margin, as this tumor is locally invasive and tends to infiltrate deep into pelvic soft tissues. There are no guidelines in the postoperative management of vulvar aggressive angiomyxoma; however due to the high recurrence rate and potential morbidity associated with undiagnosed recurrences, several authors have recommended periodic evaluations with physical examination and MR imaging up to fifteen years after treatment. ${ }^{12}$ We advised our patient for regular follow up to evaluate any signs and symptoms of local recurrence. Aggressive angiomyxomashows some immunohistochemical markers. Studied carried out by Chen et al in 5 patients concluded that tumor cells showed strong expression of vimentin, desmin, estrogen receptor(ER) and progesterone receptor(PR) on the other hand, partial or weak expression was observed for smooth muscle actin(SMA) , actin, CD34, and S-100. ${ }^{13}$ Similarly study carried out by Jingping and Chunfu concluded that aggressive angiomyxoma tended to be strongly positive for vimentin, smooth-muscle actin, and CD34 but mostly negative for S$100 .{ }^{14}$ Although the first line of treatment of aggressive angiomyxoma is surgery but when organs, such as the rectum and bladder to which the tumor may be attached, are spared as the morbidity of extensive surgery may not be justified due to its high recurrence rate even after complete resection. So hormonal therapy with $\mathrm{GnRH}$ agonists may be of value in managing cases of aggressive angiomyxoma, either primary or recurrent, which are not amenable to surgical excision. ${ }^{15}$

\section{CONCLUSION}

We conclude that angiomyxoma is a rare, locally aggressive tumor, which originates from mesenchymal tissues with the tendency of local recurrence. It usually presents as a vulval mass and its definitive diagnosis is made on histopathology. The first line of management of aggressive angiomyxoma is wide local excision with tumor free margin. As there is risk of recurrence of disease regular follow up is mandatory. We resected the tumor with no visible or palpable residual tumor and there are no signs of recurrence after six months without any hormonal therapy. 


\section{CONFLICT OF INTEREST}

No any conflict of interest.

\section{FINANCIAL DISCLOSURE}

None

\section{PATIENT CONSENT}

Written informed consent was obtained from the patient for the publication of this case report and the images.

\section{REFERENCES}

1. Bridge JA, Hogendoorn P, DM C, Bridge JA, CW P, Fletcher CD. WHO classification of tumours of soft tissue and bone. International Agency for Research on Cancer; 2013.

2. Steeper TA, Rosai J. Aggressive angiomyxoma of the female pelvis and perineum. Report of nine cases of a distinctive type of gynecologic soft-tissue neoplasm. The American journal of surgical pathology. 1983 Jul 1;7(5):463-75.PMID: 6684403

3. SenGupta SK, Bhattacharyya SK, Saha SP, Roy H, Sarkar AN. Recurrent Aggressive Angiomyxoma of The Vulva-A Rare Presentation. Journal of clinical and diagnostic research: JCDR. 2014 May;8(5):OD01.PMID: 24995218

4. Misra S, Rath TS, Nayak BL,Giri SK. Vulvalangiomyxoma: a case report. International Journal ofReproduction, Contraception, Obstetrics and Gynecology 2017;6: 3692-4.DOI: http://dx.doi.org/10.18203/23201770.ijrcog20173516

5. Zizi-Sermpetzoglou A, Myoteri D, Koulia K, Kontostolis V, Moschouris $H$, Dellaportas D. Aggressive angiomyxoma of the vulva: a bizarre perineal lesion. Case reports in oncological medicine. $2015 \mathrm{Apr}$ 22;2015. DOI: https://doi.org/10.1155/2015/292304

6. Carney JA, Headington JT, Su WD. Cutaneous myxomas: a major component of the complex of myxomas, spotty pigmentation, and endocrine overactivity. Archives of dermatology. $1986 \mathrm{Jul}$ 1;122(7):790-8.PMID: 3729510

7. letto C, Giannini A, Perutelli A, Pistolesi S, Pancetti F, et al. (2020) A 19 $\mathrm{cm}$ Angiomyxoma of the Vulva in a 45-Year-Old Woman: A Case Report. GynecolObstet Case Rep Vol.6 No.1:7DOI: 10.36648/24718165.6.1.88

8. Narang S, Kohli S, Kumar V, Chandoke R. Aggressive angiomyxoma with perineal herniation. Journal of clinical imaging science. 2014;4.PMID: 24987570
9. Rezai S, Kirby C, Chadwick E, Gottimukkala S, Chadee A. Aggressive Angiomyxoma of the Vulva in a Teenager, a Case Report and Review of Literature. ObstetGynecollnt J. 2016;4(6):00128.DOI: 10.15406/ ogij.2016.04.00128

10. Patil NG, Chavan S, Waikar M, Kalyankar V, Rathod A, Kodgire J. Aggressive (Deep) Angiomyxoma of Vagina: A Rare Case Report. INTERNATIONAL JOURNAL OF SCIENTIFIC STUDY. 2016 Aug 1;4(5):254-8.DOI: 10.17354/ijss/2016/470

11. Alomary NA, Albeeshi MZ, Al Thebaity RE, Yousef ZM, El-Boghdadly $\mathrm{SA}$. Aggressive angiomyxoma persistently misdiagnosed as an obturator hernia managed with resection and hormonal therapy: case report. Journal of Surgical Case Reports. 2020 Sep;2020(9): rjaa330.PMID: 32913627

12. Elkattah R, Sarkodie O, Otteno H, Fletcher A. Aggressive angiomyxoma of the vulva: a précis for primary care providers. Case reports in Obstetrics and Gynecology. 2013 Aug 13;2013.PMID 24073346

13. Chen $H$, Zhao H, Xie $Y$, Jin M. Clinicopathological features and differential diagnosis of aggressive angiomyxoma of the female pelvis: 5 case reports and literature review. Medicine. 2017 May;96(20).PMID: 28514296

14. Jingping Z, Chunfu Z. Clinical experiences on aggressive angiomyxoma in China (report of 93 cases). International Journal of Gynecologic Cancer. 2010 Feb 1;20(2).PMID: 20134274

15. McCluggage WG, Jamieson T, Dobbs SP, Grey A. Aggressive angiomyxoma of the vulva: dramatic response to gonadotropinreleasing hormone agonist therapy. Gynecologic oncology. 2006 Mar 1;100(3):623-5.PMID: 16246403 